\title{
Genetic and morphological study of the Black-stripe minnow, Galaxiella nigrostriata (Salmoniformes: Galaxiidae), including a disjunct population near Perth, Western Australia
}

\author{
Kimberly D. Smith ${ }^{1,2}$, Luke J. Pen ${ }^{3}$ and Brenton Knott ${ }^{1}$ \\ ${ }^{1}$ Department of Zoology, The University of Western Australia, \\ 35 Stirling Highway, Crawley, WA 6009, Australia \\ ${ }^{2}$ Present address: Murdoch University Centre for Fish and Fisheries Research, \\ Division of Science and Engineering, School of Biological Sciences and Biotechnology, \\ Murdoch University, Murdoch, WA 6150, Australia: email: ksmith@central.murdoch.edu.au \\ ${ }^{3}$ Water and Rivers Commission, Hyatt Centre, East Perth, WA 6004, Australia
}

\begin{abstract}
This study was undertaken to measure the relatedness of an outlying population of Black-stripe minnow, Galaxiella nigrostriata (Shipway), from Melaleuca Park, $25 \mathrm{~km}$ northeast of Perth, to the main populations situated some $350 \mathrm{~km}$ to the south between Augusta and Albany. Allozyme electrophoresis was used to assess genetic divergence between populations. Univariate statistical tests were employed to compare the morphology of fish from the different locations. Reproductive isolation of G. nigrostriata at EPP 173 has resulted in inbreeding and reduced heterozygosity as well as differences in morphology. Galaxiella nigrostriata throughout its range shows unusually low levels of genetic polymorphism. One polymorphic locus was identified from the 27 loci sampled. Polymorphic individuals were restricted to the southern sites; specimens from EPP 173 were entirely monomorphic. Fish from EPP 173 had longer head lengths and shorter caudal peduncles than those in the south.
\end{abstract}

Keywords: freshwater fish, low genetic variation.

\section{INTRODUCTION}

Of the ten species of freshwater fish native to southwestern Australia, six [Galaxias truttaceus, Galaxias maculatus, Galaxiella munda and Galaxiella nigrostriata (Galaxiidae); Lepidogalaxias salamandroides (Lepidogalaxiidae); and Nannatherina balstoni (Nannopercidae)] have very restricted, coastal distributions in peat wetlands between Albany $\left(35^{\circ} 02^{\prime} \mathrm{S} ; 117^{\circ} 53^{\prime} \mathrm{E}\right)$ and Augusta $\left(34^{\circ} 20^{\prime} \mathrm{S}\right.$; $115^{\circ} 09^{\prime} \mathrm{E}$ ). The other four species [Bostockia porosa (Percichthyidae), Edelia vittata (Nannopercidae), Galaxias occidentalis (Galaxidae), and Tandanus bostocki (Plotosidae)] have wider distributions between Two Peoples Bay (34 $\left.57^{\circ} \mathrm{S} ; 118^{\circ} 11^{\prime} \mathrm{E}\right)$ and the Moore River $\left(31^{\circ} 03^{\prime} \mathrm{S}\right.$; $115^{\circ} 35^{\prime} \mathrm{E}$ ) (Allen 1982; Morgan et al. 1996, 1998). Of these ten species, eight are endemic to southwestern Australia, while G. maculatus and G. truttaceus, both with marine larval stages in some populations, also occur in Tasmania and Victoria with the geographical range of $G$. maculatus extending to New South Wales, South Australia, Queensland, New Zealand, southern South America, and the Chatham and the Falkland Islands (Allen 1982; Berra et al. 1996; McDowall 1996).
With the discovery in recent years of outlier populations of $G$. munda between Gingin ( $31^{\circ} 21^{\prime} \mathrm{S}$; $115^{\circ} 54^{\prime} \mathrm{E}$ ) and Muchea (31 $35^{\circ} \mathrm{S}$; $115^{\circ} 58^{\prime} \mathrm{E}$ ) (Allen 1982), of N. balstoni at Gingin (Morgan et al. 1996, 1998), and of G. nigrostriata at Bunbury (33'19'S; $115^{\circ} 38^{\prime} \mathrm{E}$ ) (Morgan et al. 1996, 1998) and in wetland EPP 173 in Melaleuca Park $\left(31^{\circ} 42^{\prime} S\right.$; $\left.115^{\circ} 57^{\prime} \mathrm{E}\right)$, northeast of Perth, Western Australia (Smith et al. 2002) (Figure 1), there arises the question of how related are any of these widely disjunct northern populations to those from the centre of distribution of that species. The focus in this study is on the Black-stripe minnow, Galaxiella nigrostriata (Shipway 1953) (Teleostei: Salmoniformes: Galaxiidae). Galaxiella nigrostriata was originally described as a subspecies of the southeastern Australian species, Galaxias pusillus. Subsequently, McDowall (1978) erected the genus Galaxiella for the three species of diminutive galaxiids with horizontal body stripes, G. nigrostriata, G. munda and G. pusilla. Supplementary descriptions of $G$. nigrostriata have been provided by McDowall and Frankenberg (1981), Gill and Neira (1994), and Berra and Allen (1989) clarified the morphological differences between $G$. nigrostriata and G. munda. 
Growth, size composition, diet and aspects of the reproductive biology of $G$. nigrostriata from the main area of distribution have been documented by Pen et al. (1993), while dietary studies were undertaken by Pusey and Bradshaw (1996).

The present study determined the relatedness of G. nigrostriata from EPP 173 to specimens from within the main area of distribution of the species. Allozyme electrophoresis was used to document genetic polymorphism and provide a basis for comparison of heterozygosity and genetic identity between sites. Morphometric analyses were used to compare the physical similarity of specimens from different geographical locations. We conclude the paper by considering the possible period of time that the northern population of G. nigrostriata has been isolated in EPP 173.

\section{MATERIALS AND METHODS}

\section{Collection of Fish}

Fish were collected from EPP 173 throughout the period May to September, 1996. Specimens were collected from the lower southwest between May and July, 1996; i.e. from roadside pools beside Chesapeake Road $\left(34^{\circ} 42^{\prime} S ; 116^{\circ} 07^{\prime} \mathrm{E}\right)$ within the Gardner River watershed in the D'Entrecasteaux National Park and, from Scott Road near Lake Jasper $\left(34^{\circ} 25^{\prime} \mathrm{S} ; 115^{\circ} 45^{\prime} \mathrm{E}\right)$ in the Donnelly River catchment of the Shannon National Park.

Fish were collected by dragging either a pond net, diameter $85 \mathrm{~cm}, 100 \mathrm{~mm}^{2}$ stretched mesh, or a $5 \mathrm{~m}$ wide purse seine net of $9 \mathrm{~mm}^{2}$ stretched mesh through open water. Low numbers of fish were sampled in order to cause a minimum impact upon the small resident populations and consequently, where possible, specimens were used in several facets of the study.

\section{Electrophoresis}

Specimen numbers were as follows: EPP 173, 24 fish; Chesapeake Road, 16; Lake Jasper, 11. Skeletal muscle tissue was removed under a dissection microscope, homogenised with extractant (2:1, extractant: tissue by volume; extractant of $0.28 \mathrm{M}$ sucrose, $0.1 \%(\mathrm{v} / \mathrm{v})$ mercaptoethanol, $0.02 \%(\mathrm{w} / \mathrm{v})$ bromophenol blue in $0.02 \mathrm{M}$ tris, $\mathrm{pH} 8$ ) in ceramic depression wells, using a glass test tube. The extracts were soaked onto $5 \times 6 \mathrm{~mm}$ rectangles of chromatography paper and stored overnight at $70^{\circ} \mathrm{C}$. Extracts were prepared over an ice pack on the day prior to the run to minimise deterioration of the enzymes.

Gels contained between 18 and $19.5 \mathrm{~g}$ of hydrolysed potato starch (Starch Art) and approximately $165 \mathrm{~mL}$ of the appropriate buffer solution. Starch gels were prepared 24 hours prior to runs which were made at varying voltages and currents, for different periods of time according to the requirements of each buffer solution. Staining for enzymes followed the protocols described in Richardson et al. (1986). For loci encoding enzymes exhibiting polymorphisms, data were collected running a maximum of 14 individuals from a site on a gel together with a minimum of two individuals of known genotype from an alternative location.

Allelic frequencies at the polymorphic locus were calculated and estimates of heterozygosity obtained according to the method of Nevo (1978). Nei's index of genetic identity was calculated to quantify the similarity between the samples (Nei 1978).

\section{Morphometric Analyses}

Sample sizes were as follows: EPP 173, 11; Lake Jasper, 16; Chesapeake Road, 36. Eight measurable characters were assessed for each fish using a dissecting microscope: total length (snout to posterior margin of tail $=T L$ ), head length $(H L)$, eye diameter (ED), body depth (BD), eye to snout length (E-S), caudal depth $(C D)$, caudal length $(C L)$, length of base of anal fin (FL) and four countable ray numbers (in the pectoral, anal, dorsal and tail fins).

To eliminate the risk of errors due to preservation artefacts only very recently dead and/or anaesthetised fish were used for analysis. In order to determine the effect of sex on character variation, specimens from the Lake Jasper site were humanely killed by an overdose of anaesthetic, dissected and their sex identified by the presence of ovary or testis within the body cavity. Each character was tested for sexual dimorphism using an unpaired 2-tailed $t$ test. With the exception of body depth (BD), each character was independent of sex $(95 \%$ confidence interval). Given the limited number of specimens available, and the need to use them in a number of aspects of this study, BD was eliminated from the analyses, with the remaining analyses conducted independent of sex. Fish were not sufficiently abundant to permit the comparison of only similarsized specimens. Linear regression analyses were performed using the Chesapeake Road sample to test whether the relationship of each measurable character to total length was isometric; all characters increased linearly with body size enabling different sized specimens to be compared by standardising character values. Measurable characters were standardised by dividing them by body length of the specimen. All specimens were longer than $13.2 \mathrm{~mm}$ standard length, the length by which all fin rays are formed (Gill and Neira 1994). Levene's homogeneity of variance test was applied to qualify the assumption that means for each character were normally distributed within samples. One-way analyses of variance were calculated between sites for each of the meristic and standardised measurable characters. 
Table 1 Proteins showing resolvable banding in G. nigrostriata and buffer systems giving best resolution.

\begin{tabular}{|c|c|c|c|}
\hline Protein & Buffer type & No. Loci & Variability \\
\hline Adenosine deaminase & TEB & 1 & $M$ \\
\hline Adenylate kinase & TC8 & 2 & M \\
\hline Alcohol dehydrogenase & TM & 1 & M \\
\hline Creatine kinase & TC8 & 2 & M \\
\hline$\alpha$ Esterase & $\mathrm{TM}$ & 1 & $\mathrm{M}$ \\
\hline$\beta$ Esterase & TM & 2 & M \\
\hline Glucose 6-phosphate dehydrogenase & TEB & 1 & M \\
\hline$\alpha$-Glycerophosphate dehydrogenase & TEB & 2 & $\mathrm{M}$ \\
\hline Icocitrate dehydrogenase & TC8 & 1 & $\mathrm{M}$ \\
\hline Lactate dehydrogenase & TM & 2 & $M$ \\
\hline Leucine aminopeptidase & TEB & 1 & M \\
\hline Malate dehydrogenase & TM & 2 & $1 \mathrm{M}, 1 \mathrm{P}$ \\
\hline \multicolumn{4}{|l|}{ Peptidases } \\
\hline L-Leucyl-glycyglycine & TM & 1 & M \\
\hline L-Leucyl-Proline & TM & 1 & $\mathrm{M}$ \\
\hline L-Leucyl-L-Tyrosine & TM & 1 & M \\
\hline L-Valyl-Leucine & TEB & 1 & M \\
\hline 6-Phosphogluconate dehydrogenase & TEB & 1 & M \\
\hline Phosphoglucose isomerase & TEB & 1 & $\mathrm{M}$ \\
\hline Phosphoglucomutase & TEB & 1 & M \\
\hline Superoxide dismutase & A & 2 & M \\
\hline
\end{tabular}

\section{RESULTS}

\section{Electrophoresis}

Polymorphism was very low; of the 27 loci encoding 20 enzymes clearly resolvable, just one polymorphism was identified (Table 1) - malate dehydrogenase exhibited 3-banded dimeric variants for two alleles. The level of polymorphism recorded for $G$. nigrostriata from both sites within its main area of distribution was 3\%; the EPP 173 specimens were entirely monomorphic (Table 2). An additional 11 enzymes assayed showed unresolvable banding patterns and remained ambiguous despite repeated efforts combining liver and muscle tissue, using alternative buffers and increasing the concentration of the stain twofold.

Heterozygote frequencies of $\mathrm{Mdh}$ at the Chesapeake Road and Lake Jasper sites fitted frequencies expected under Hardy-Weinberg equilibrium ( $p>0.01)$. There were significant differences in allele frequencies at the polymorphic locus between all sites $(p<0.05)$. Average overall heterozygosity at Chesapeake Road and Lake Jasper was 0.018 and 0.008 respectively. Nil heterozygosity was recorded at EPP 173 . The values obtained for

Table 2 Allele frequencies at the malate dehydrogenase locus; the only locus found to be polymorphic in Black-stripe minnow.

\begin{tabular}{llll}
\hline Collection site & Sample size & "Slow" & "Fast" \\
\hline Melaleuca Park & 24 & 1 & 0 \\
Chesapeake Road & 16 & 0.125 & 0.875 \\
Lake Jasper & 11 & 0.5 & 0.5 \\
\hline
\end{tabular}

Table 3 Between-site comparisons of Nei's genetic similarity (I).

\begin{tabular}{ll}
\hline Comparison & I \\
\hline Chesapeake Road versus Lake Jasper & .996 \\
Chesapeake Road versus EPP 173 & .999 \\
Lake Jasper versus EPP 173 & .997 \\
\hline
\end{tabular}

Nei's (1978) similarity indices were very close to the theoretical maximum value of one between all sites (Table 3).

\section{Morphometric analyses}

The values of each measurable character increased linearly with increasing total body length; correlation co-efficients were very close to one (Table 4). Standardised head lengths within the EPP 173 population (mean 19.6\% B.L.) were found to be significantly larger $(p=0.02)$ than those from fish collected near Lake Jasper (mean $18.5 \%$ B.L.) (Table 5). Similarly, standardised caudal peduncle lengths were shorter at EPP 173

Table 4 Correlation co-efficients of linear regression analyses defining the relationship between each measurable character and total body length.

\begin{tabular}{ll}
\hline Character & Correlation co-efficient \\
\hline Head length & $r=0.952$ \\
Eye diameter & $r=0.763$ \\
Eye-nose distance & $r=0.870$ \\
Caudal depth & $r=0.669$ \\
Caudal length & $r=0.860$ \\
\hline
\end{tabular}


Table 5 Range and mean ( \pm standard deviation) of morphological characters used to compare G. nigrostriata from three locations.

\begin{tabular}{|c|c|c|c|c|c|c|}
\hline \multirow[b]{2}{*}{$\mathrm{TL}(\mathrm{mm})$} & \multicolumn{2}{|c|}{ EPP $173 n=11$} & \multicolumn{2}{|c|}{ Lake Jasper $N=16$} & \multicolumn{2}{|c|}{ Chesapeake Road $N=35$} \\
\hline & $20.9-34.0$ & $(28.4 \pm 4.7)$ & $25.9-35.8$ & $(30.6 \pm 2.9)$ & $17.8-43.0$ & $(32.4 \pm 5.6)$ \\
\hline HL (\% BL) & $17.7-21.3$ & $(19.6 \pm 0.99)$ & $16.7-20.8$ & $(18.5 \pm 1.07)$ & $15.9-21.2$ & $(18.8 \pm 1.04)$ \\
\hline $\mathrm{ED}(\% \mathrm{BL})$ & $4.8-6.8$ & $(6.0 \pm 0.56)$ & $4.7-6.1$ & $(5.5 \pm 0.40)$ & $4.7-8.1$ & $(5.9 \pm 0.70)$ \\
\hline $\mathrm{E}-\mathrm{N}(\% \mathrm{BL})$ & $3.6-5.2$ & $(4.4 \pm 0.53)$ & $3.5-5.0$ & $(4.2 \pm 0.46)$ & $2.9-5.9$ & $(4.3 \pm 0.51)$ \\
\hline$C D(\% B L)$ & $4.8-5.5$ & $(5.1 \pm 0.30)$ & $3.8-6.1$ & $(4.9 \pm 0.52)$ & $2.4-9.4$ & $(4.9 \pm 0.96)$ \\
\hline $\mathrm{CL}(\% \mathrm{BL})$ & $14.1-16.8$ & $(16.0 \pm 0.80)$ & $15.5-18.9$ & $(16.8 \pm 0.99)$ & $14.4-24.9$ & $(17.4 \pm 1.75)$ \\
\hline Pectoral fins & $11-13$ & $12 \pm 1.0$ & $11-13$ & $11.9 \pm 0.5$ & $10-13$ & $12 \pm 0.6$ \\
\hline Anal fins & $7-10$ & $(9.3 \pm 0.9)$ & $9-10$ & $(9.5 \pm 0.5)$ & $7-10$ & $(9.4 \pm 1.0)$ \\
\hline Dorsal fins & $7-8$ & $(7.4 \pm 0.5)$ & $5-7$ & $(6.4 \pm 0.7)$ & $5-8$ & $(6.8 \pm 0.8)$ \\
\hline Tail fins & $14-15$ & $(14.5 \pm 0.5)$ & $14-15$ & $(14.2 \pm 0.4)$ & $14-15$ & $(14.1 \pm 0.3)$ \\
\hline
\end{tabular}

(mean 16\% B.L.) compared with the Chesapeake Road (mean $17.4 \%$ B.L.) $(\mathrm{p}=0.02)$.

\section{DISCUSSION}

Galaxiella nigrostriata recorded approximately $3 \%$ polymorphism; of 27 loci assayed, only one was polymorphic. This value, compared to values between 15 and $20 \%$ commonly recorded from vertebrates, is very low (Nevo 1978). For example, Watts et al. (1995), recorded $20 \%$ of loci polymorphic in $G$. occidentalis, a relatively widespread galaxiid endemic to southwestern Australia. While genetic similarity between fish from the three different locations sampled is very high and does not reflect geographic distance, the northern population, in contrast to the main population is entirely monomorphic, indicating that reproductive isolation and small population size at EPP 173 has possibly resulted in inbreeding effects. Furthermore, while differences in two morphological characters were not consistent between EPP 173 specimens and those from the southern locations, the fact that there were no differences between fish collected from within the main southern area of distribution indicates that isolation at EPP 173 is influencing the appearance of the fish.

These small differences which have arisen between the EPP 173 population of G. nigrostriata and the main populations indicate that the population at EPP 173 has been reproductively isolated for enough generations for genetic and morphological divergence to occur. Since widescale urban and rural development of the Swan Coastal Plain, and the subsequent alteration of intervening wetlands commenced early this century (Bekle and Gentilli 1966; Seddon 1972; Wrigley et al. 1988; Halse 1989), G. nigrostriata at EPP 173 is likely to have been isolated for at least several decades. We conclude that the population of G. nigrostriata at EPP 173 is not the result of recent colonisation, but is a long established population which has persisted there presumably because this wetland has not been subject yet to significant degradation.

Given the rapid (one year) life cycle of this species (Pen et al. 1993), and the likelihood that the population at EPP 173 has been isolated for several decades, it is surprising that genetic differentiation is not more pronounced. For example, the Galaxias genotype has been shown capable of quite rapid evolution as a result of landlocking behind hydro-electric impoundments (Fulton 1978) and segregation in different river systems (Watts et al. 1995). Indeed, small levels of environmental heterogeneity were regarded by Wallis et al., (2001) to be a sufficient reason explaining genetic divergence in populations of Galaxias vulgaris Stokell in the South Island of New Zealand. However, in G. nigrostriata, genetic divergence appears to have been limited by low levels of genetic variation within the genome of this species.

There are several possible explanations for the peculiarly low levels of genetic polymorphism detected across the range of $G$. nigrostriata, and subsequently for the absence of pronounced genetic divergence between populations. Although $G$. nigrostriata can occur on two widely separated geomorphic units (namely the Swan and Scott Coastal Plains), it is known only from waters with a narrow range of physical and chemical conditions (Smith et al. 2002; Knott et al. 2002). Although such ephemeral, acidic ( $\mathrm{pH} 3.25-5.5$ ) black-water (colour $>1200 \mathrm{TCU}$ ) habitats may embody physiologically extreme conditions in comparison with other Australian freshwater habitats, they probably are reasonably constant in their physical and chemical conditions. The narrow range of environmental conditions (i.e. uniform habitat) occupied by $G$. nigrostriata may have caused directional selection for homozygosity and the fixation of a small range of genotypes. The resulting lack of heterozygosity may have subsequently reduced the ability of this species to adapt to the rapid environmental changes to wetland habitats induced by Europeans this century. 
Low levels of genetic variation are likely to reflect the degree to which habitat alteration has reduced the number of $G$. nigrostriata populations on the Swan Coastal Plain, causing inbreeding. Several northern outlier populations of freshwater fishes mainly from the lower south west indicate that stocks remaining at EPP 173 and within the narrow strip of southwest coastal peat flats represent only a minor proportion of the original population size. The absence of heterozygotes at EPP 173 indicates the vulnerability of this species to inbreeding. Heterozygosity within the polymorphic locus of fish from within the main population does not indicate inbreeding; inter-breeding is possibly facilitated by extensive seasonal flooding which causes large wetland areas along the south coast to become connected. Within this main population, however, overall heterozygosity is unusually low and is comparable to that of fishes which have had histories of population depletion.

Low levels of genetic polymorphism $(6 \%)$ and overall heterozygosity (0.013) have also been detected in the North American paddlefish, Polydon spathula (Carlson et al. 1982). P. spathula, like G. nigrostriata, occurs in a very narrow range of environmental conditions and has been significantly adversely affected by habitat alteration and is now absent from major areas of its original range (Carlson et al. 1982). The low (4\%) level of polymorphism of Sardinella aurita, abundant throughout the Mediterranean and off Western Africa, (Chikhi et al. 1998), has been attributed to a combination of collapses in fish stocks caused by over fishing, variations in reproductive success and possibly mass extinctions caused by ancient glaciation cycles.

The northern population of G. nigrostriata could have been established in comparatively recent times, explaining the lack of genetic divergence from the main population. Colonisation could have been facilitated via a spring-fed stream which during winter and early spring connects EPP 173 with Ellen Brook, a tributary of the Swan River. However, the nearest documented population of $G$ nigrostriata is over $200 \mathrm{~km}$ away at Bunbury, and the wetland harbouring this population is widely separated from the Swan River catchment.

However, the present distribution pattern of the endemic fish fauna, and particularly the disjunct patterns of three species with northern outlier populations [G. nigrostriata at EPP 173, G. munda (Allen 1982) and N. balstoni (Morgan et al. 1998) near Gingin] and with specialised breeding requirements (acid, black, temporary water), suggests that previously species had a wider distribution through the southwest corner of Australia, particularly along the Swan Coastal Plain. The presence of Europeans has had a markedly deleterious impact, with extensive urban and rural developments leading to alteration of intervening wetlands. Consequently, the population of G. nigrostriata at EPP 173 may be of long-standing but it is impossible as yet to estimate the length of the period of complete isolation - likely to have been several decades, at least. At least one species of invertebrate, Rak obtusus (Cladocera), also an inhabitant of EPP 173, is otherwise only recorded from wetlands in the lower southwest; further descriptions of aquatic invertebrates from the wetlands at Melaleuca Park could reveal more relictual faunae. More detailed genetic studies, involving DNA assays and comparisons between the other endemic freshwater fishes, some with outlying populations, are essential to provide additional insight into the effects of wetland alteration upon the freshwater piscine fauna in Western Australia.

\section{ACKNOWLEDGEMENTS}

We gratefully acknowledge the assistance of: Jeff Kite and Sharon Stratico, Water and Rivers Commission, Perth, who provided strong support for studies on EPP 173; Howard Gill and Dave Morgan, Murdoch University, Perth, for providing specimens as well as data from their research into the distributions of freshwater fish in south-western Australia.

Funding from both the Department of Zoology, The University of Western Australia, and the Water and Rivers Commission, Perth, is also gratefully acknowledged.

\section{REFERENCES}

Allen, G.R. (1982). A Field Guide to Inland Fishes of Western Australia. Western Australian Museum. 86 pp.

Bekle, H. and Gentilli, J. (1966). History of Perth Lakes. Early Days; Royal Western Australian Historical Society Journal 10: $5 \mathrm{pp}$.

Berra, T.M. and Allen, G.R. (1989). Clarification of the differences between Galaxiella nigrostriata (Shipway 1953) and Galaxiella munda McDowall, 1978 (Pisces: Galaxiidae) from Western Australia. Records of the Western Australian Museum 14: 293-297.

Berra, T. M., Crowley, L.E.L. M Crowley, Ivantsoff, W. and Fuerst, P. A. (1996). Galaxias maculatus: an explanation of its biogeography. Marine and Freshwater Research 47 : 845-849.

Carlson, D.M., Kettler, M.K., Fisher, S.E. and Whitt, G.S. (1982). Low genetic variability in paddlefish populations. Copeia 1982: 721-725.

Chikhi, L., Bonhomme, F, and Agneese, J.F. (1998). Low genetic variability in a widely distributed and abundant clupeid species, Sardinella aurita. New emperical results and interpretations. Journal of Fish Biology 52: 861-878.

Fulton, W. (1978). A description of a new species of Galaxias (Pisces: Galaxiidae) from Tasmania. 
Australian Journal of Marine and Freshwater Research 29 : 109-148.

Gill, H.S. and Neira, F.J. (1994). Larval descriptions of three galaxiid fishes endemic to southwestern Australia: Galaxias occidentalis, Galaxiella munda and Galaxiella nigrostriata (Salmoniformes: Galaxiidae). Australian Journal of Marine and Freshwater Research 45: 1307-1317.

Halse, S.A. (1989). Wetlands of the Swan Coastal Plain; past and present. In G.Lowe (ed.), Proceedings of the Swan Coastal Plain Groundwater Management Conference: 105-112. West Australian Water Resources Council.

Knott, B., Jasinska, E.J. and Smith K.D. (2002). Limnology and aquatic fauna of EPP 173, Melaleuca Park, refuge for an outlier population of the Black-stripe minnow Galaxiella nigrostriata (Pisces: Galaxiidae) in southwestern Australia. Records of the Western Australian Museum 21: 291-298.

McDowall, R.M. (1978). A new genus and species of galaxiid fish from Australia (Salmoniformes: Galaxiidae). Journal of the Royal Society of New Zealand 8: 115-124.

McDowall, R.M. (1996). Freshwater Fishes of Southeastern Australia. Reed Books, Sydney. 247 pp.

McDowall, R.M. and Frankenberg, R.S. (1981). The galaxiid fishes of Australia (Pisces : Galaxiidae). Records of the Australian Museum 33: 443-605.

Morgan, D.L., Gill, H.S. and Potter, I.C. (1996). The Distribution of Freshwater Fish in the Southwestern Corner of Australia. Water Resource Technical Series Report WRT 4, Water and Rivers Commission: 26 pp.

Morgan, D.L., Gill, H.S. and Potter, I.C. (1998). The distribution, identification and biology of freshwater fishes in south-western Australia. Records of the Western Australian Museum. Suppl. No. 56: 97 pp.

Nei, M. (1978). Estimation of average heterozygosity and genetic distance from a small number of individuals. Genetics 89: 583-590.
Nevo, E. (1978). Genetic variation in natural populations: pattern and theory. Theoretical Population Biology 13: 121-177.

Pen, L.J., Gill, H.S., Potter, I.C. and Humphreys, P. (1993). Growth, age composition, reproductive biology and diet of the Black-stripe minnow Galaxiella nigrostriata (Shipway), including comparisons with two Galaxiella species. Journal of Fish Biology 43: 847-863.

Pusey, B.J. and Bradshaw S.D. (1996). Diet and dietary overlap in fishes of temporary waters of southwestern Australia. Ecology of Freshwater Fish 5: 183-194.

Richardson, B., Baverstock, P. and Adams, M. (1986). Allozyme Electrophoresis. Academic Press, London.

Seddon, G. (1972). Sense of Place. The University of Western Australia Press, Nedlands.

Smith, K., B. Knott and Jasinska, E.J. (2002). Biology of the Black-stripe minnow, Galaxiella nigrostriata (Shipway), in an acidic, black-water lake in Melaleuca Park near Perth, Western Australia. Records of the Western Australian Museum 21: 277-284.

Wallis, G.P., Judge, K.F., Bland, J., Waters, J.M. and Berra, T.M. (2001). Genetic divergence in New Zealand Galaxias vulgaris sensu lato (Teleostei: Osmeriformes: Galaxiidae): a test of a biogeographic hypothesis. Journal of Biogeography 28: 59-67.

Watts, R.J., Storey, A.W., Hebert, D.R. and Edward, D.H.D. (1995). Genetic and morphological differences between populations of the western minnow, Galaxias occidentalis. Journal of Marine and Freshwater Research 46: 769-777.

Wrigley, T.J., Chambers, J.M. and McComb, A.J. (1988). Nutrient and gilvin levels in waters of Coastal Plain wetlands in an agricultural area of Western Australia. Australian Journal of Marine and Freshwater Research 39: 685-694.

Manuscript received 25 July 2001; accepted 29 May 2002 